\title{
Talcage by medical thoracoscopy for primary spontaneous pneumothorax is more cost-effective than drainage: a randomised study
}

\author{
J-M. Tschopp*, C. Boutin*, P. Astoul ${ }^{\#}$, J-P. Janssen ${ }^{\Uparrow}$, S. Grandin*, C-T. Bolliger ${ }^{+}$, L. Delaunois ${ }^{\S}$, \\ P. Driesen ${ }^{f}, \mathrm{G}$. Tassi**, A-P. Perruchoud ${ }^{\star}$, and the ESMEVAT team
}

Talcage by medical thoracoscopy for primary spontaneous pneumothorax is more cost-effective than drainage: a randomised study. J-M. Tschopp, C. Boutin, P. Astoul, $J$-P. Janssen, S. Grandin, C-T. Bolliger, L. Delaunois, P. Driesen, G. Tassi, A-P. Perruchoud, and the ESMEVAT team. C) ERS Journals Ltd 2002.

ABSTRACT: Simple thoracoscopic talcage (TT) is a safe and effective treatment of primary spontaneous pneumothorax (PSP). However, its efficacy has not previously been estimated in comparison with standard conservative therapy (pleural drainage (PD)).

In this prospective randomised comparison of two well-established procedures of treating PSP requiring at least a chest tube, cost-effectiveness, safety and pain control was evaluated in 108 patients with PSP (61 TT and 47 PD).

Patients in both groups had comparable clinical characteristics. Drainage and hospitalisation duration were similar in TT and PD patients. There were no complications in either group. The immediate success rate was different: after prolonged drainage ( $>7$ days), 10 out of 47 PD patients, but only 1 out of 61 TT patients required a TT as a second procedure. Total costs of hospitalisation including any treatment procedure were not significantly different between TT and PD patients. Pain, measured daily by visual analogue scales, was statistically higher during the first 3 days in TT patients but not in those patients receiving opiates. One month after leaving hospital, there was no significant difference in residual pain or full working ability: 20 out of $58(34 \%)$ versus 10 out of $47(21 \%)$ and 36 out of $61(59 \%)$ versus 26 out of 39 $(67 \%)$ in TT versus PD groups, respectively. After 5 yrs of follow-up, there had been only three out of $59(5 \%)$ recurrences of pneumothorax after TT, but 16 out of $47(34 \%)$ after conservative treatment by PD. Cost calculation favoured TT pleurodesis especially with regard to recurrences.

In conclusion, thoracoscopic talc pleurodesis under local anaesthesia is superior to conservative treatment by chest tube drainage in cases of primary spontaneous pneumothorax that fail simple aspiration, provided there is efficient control of pain by opioids.

Eur Respir J 2002; 20: 1003-1009.

*Centre Valaisan de Pneumologie, Montana, Switzerland. " Service de Pneumologie, Hôpital de la Conception, Marseille, France. "Afdeling Longziekten, Canisius Wilhelmina Ziekenhuis, Nijmegen, the Netherlands. ${ }^{+}$Abteilung für Pneumologie, Universitätskantonsspital, Basel, Switzerland. ${ }^{\$}$ Service de Pneumologie, Cliniques Universitaires UCL de Mont-Godinne, Yvoir, Belgium. ${ }^{f} \mathrm{St}$ Elisabeth ZH, Turnhout, Belgium. **Divisione di Pneumologia, Spedali Civili, Brescia, Italy.

Correspondence: J.M. Tschopp, Centre Valaisan de Pneumologie, CH 3962 Montana, Switzerland.

Fax: 41276038181

E-mail: Elisabeth.voland@admin.vs.ch

Keywords: Chest tube drainage cost-effectiveness

primary spontaneous pneumothorax randomised controlled study talc pleurodesis

thoracoscopy

Received: September 62001

Accepted after revision: April 302002

This study was supported by the Lancardis Foundation, 1920 Martigny, Switzerland.
Primary spontaneous pneumothorax (PSP) is a condition with high morbidity and high recurrence rate, often requiring hospital admission. The incidence of a first episode of spontaneous pneumothorax (SP) has been calculated as 8.6 per 100,000 persons per year and of recurrent SP as 8.3 per 100,000 [1]. There is no consensus about treatment of SP, especially of the first event. However, there is general consensus that some treatment is mandatory with second or recurrent SP. Treatment options include pleurodesis, pleurectomy associated with bullectomy by thoracotomy or videoassisted thoracoscopic surgery (VATS), or thoracoscopic talcage (TT) by medical thoracoscopy. It has been shown both clinically $[2,3]$ and experimentally [4] that talc is the best sclerosing agent currently available for obtaining pleurodesis. However, many therapeutic approaches [5-8] combine talc or surgical pleurodesis with bullectomy or bleb resection or coagulation, although it has not been shown that specific treatment of blebs or bullae improves the outcome of pleurodesis. JANSSEN et al. [9] showed that there was no difference in videothoracoscopic appearance between first and recurrent pneumothorax and concluded that the presence of bullous lesions did not predict recurrence. Recently, a prospective study [10] showed that for complicated pneumothorax, defined as recurring or persistent pneumothorax, simple TT under local anaesthesia prevented recurrence of SP. In a retrospective study, SCHRAmel et al. [11] showed that VATS was more cost-effective than conservative management in primary and secondary SP. However, there has been no prospective study on the management of PSP that has included assessment of costeffectiveness and pain control. 
The prospective randomised trial reported here was designed to compare the short- and long-term efficacy of TT under local anaesthesia with that of chest tube drainage. Side-effects, recurrence rate and pain felt by the patient during and after each procedure were prospectively assessed, and the costs of the two procedures was calculated as precisely as possible. With the opportunity of performing a European multicentre study, the authors also evaluated how clinicians use analgesics for optimal pain control after the procedures, and whether TT is more painful than a conservative treatment such as chest tube drainage. In addition, residual pain, working ability 1 month after leaving the hospital and all the recurrences of pneumothorax at long-term follow-up were assessed.

\section{Materials and methods}

\section{Study design and data collection}

From January 1995-November 1997, all patients presenting with a PSP were included in the study if they were $\leqslant 50 \mathrm{yrs}$ and had a large pneumothorax ( $>5 \mathrm{~cm}$ at the apex requiring a chest tube drainage), or a pneumothorax that failed attempted simple aspiration according to previous published guidelines [12]. Patients with a pneumothorax and bullae $>5 \mathrm{~cm}$ diameter or secondary SP (i.e. iatrogenic, traumatic or due to concomitant lung disease) were excluded.

The study received approval of each local ethical committee. Patients gave written informed consent and were randomised to either pleural drainage (PD) or TT by using sealed envelopes. All data were collected prospectively by computerised questionnaire and then pooled in one centre (C. Boutin; complications, daily pain assessment, drainage duration and hospital stay, total hospitalisation costs, immediate and long-term recurrence rate at follow-up). Patients were reviewed at $1,6,12$ and 18 months after intervention and were specifically asked about residual pain and full working ability 1 month after leaving the hospital. For the purpose of the study, recurrence of SP was defined as a relapse of pneumothorax requiring any further intervention, either immediately or during a second hospitalisation. Long-term follow-up was obtained by telephone contact with the general practitioner or the patient.

\section{Thoracoscopy}

Thoracoscopy was standardised as follows: patients were premedicated with atropine $(0.5 \mathrm{mg})$ and received titrated midazolam and pethidine or morphine during the procedure under careful supervision and continuous monitoring of blood pressure, electrocardiogram, oxygen saturation and end tidal carbon dioxide pressure; patients breathed spontaneously with supplementary oxygen on request; no general anaesthesia was used at any time.

Thoracoscopy was carried out in the lateral decubitus position under local anaesthesia with $1 \%$ lignocaine. A 7-mm trocar was inserted into the fourth or fifth intercostal space in midaxillary line. A $0^{\circ}$ optical telescope was inserted and connected to a video camera and monitor. The visceral pleura were carefully inspected using supplemental air insufflation where necessary. No electrocoagulation, stapling or ligation of any parenchymal lesions was carried out. Sterile asbestos-free talc ( $2 \mathrm{~g})$ was insufflated particularly to the apex. At the end of the procedure a drain (24-28 French gauge) was inserted through the sixth intercostal space in the midaxillary line and connected to underwater seal suction with a negative pressure of $20 \mathrm{cmH}_{2} \mathrm{O}$ for $\geqslant 2$ days or until air leakage stopped. When an air leak persisted for $>7$ days, another procedure was perfomed and the case was considered as an immediate failure. The authors waited 1 week before proposing a second intervention in order to optimise the chances of success in both groups and to avoid overtreating failed cases of conservative treatment.

\section{Chest tube drainage}

In both groups, patients were treated with a chest tube of the same size (24-28 French gauge) connected to a water seal device. No suction was used initially in the PD group, but suction was applied after $12 \mathrm{~h}$ if the lung failed to re-expand. The chest drain was removed when bubbling had stopped for $>24 \mathrm{~h}$ and the lung was fully re-expanded.

\section{Cost calculation}

Cost calculation was made by taking into account all the costs of each procedure and related hospitalisation, except equipment depreciation costs. Since this was a multicentre study, a standardised method of cost calculation was used. All the economic parameters were recorded for each patient and the data were centralised in Marseille. French tariffs at Conception Hospital, Marseille, France were taken as reference. Details have been published previously [13]. In brief, costs can be divided into procedure costs (TT or PD) and hospitalisation costs. However, these included only the total costs of the first hospital stay for treatment of pneumothorax or its immediate recurrence and several patients were treated for late recurrences of pneumothorax in other hospitals not belonging to the study group.

For TT or PD the costs between centres was standardised as follows (table 1): total drug and material consumption was calculated including disposable and reusable material (assuming depreciation over a period of $5 \mathrm{yrs}$ ) and $2 \mathrm{~h}$ use of an endoscopic suite in case of talc poudrage; for each procedure, the mean time a professional spent treating six patients was calculated and rounded up to the highest last $5 \mathrm{~min}$ (for PD, $20 \mathrm{~min}$ of a physician's and $30 \mathrm{~min}$ of a nurse's time; for TT, $50 \mathrm{~min}$ of a consultant anaesthetist, $30 \mathrm{~min}$ of a pulmonologist and a resident physician, $210 \mathrm{~min}$ of an anaesthesia nurse, $125 \mathrm{~min}$ of a specialised nurse and a room assistant).

Costs of hospital stay varied between patients and 
Table 1. - Costs of procedures

\begin{tabular}{lccc}
\hline Professional (time min) & Thoracoscopic talcage euros & Professional (time min) & Pleural drainage euros \\
\hline Pulmonologist (30) & 20.55 & Pulmonologist (20) & 13.70 \\
Resident physician (30) & 6.60 & & \\
Anaesthetist (50) & 34.20 & & \\
Anaesthesia nurse (210) & 62.55 & Nurse (30) & 7.95 \\
Room nurse (125) & 33.15 & Total & \\
Room assistant (125) & 26.20 & Local anaesthesia $^{\S}$ & 4.05 \\
Total & 183.25 & Material $^{\S}$ & 24.55 \\
Anaesthesia material $^{+}$ & 83.05 & Total & 50.25 \\
Endoscopic suite costs $^{+}$ & 125.80 & 392.10 & \\
\hline Total & & & \\
\hline
\end{tabular}

${ }^{\#}$ : including time to check the patient after thoracosocopic talcage; ${ }^{\top}$ : including time to clean the room after the procedure; ${ }^{+}$: including drugs, disposable material, linen, reusable equipment (5 yrs depreciation); ${ }^{\S}$ : endoscopic suite building investments (10 yrs depreciation).

included routine blood tests, blood gas tensions, daily chest radiographs (before and after intervention), and dressing changes every 3 days. Daily hospitalisation manpower costs were calculated as $10 \mathrm{~min}$ of physician's and 120 min of nurse's time.

To simplify the calculation, 20 patients in each group were randomly selected from the central database in Marseille and their total mean cost was calculated. The costs of repeat talcage in the event of procedure failure were calculated as a mean per patient. There were four out of 20 secondary talcages in the 20 PD patients and none in the 20 TT patients.

\section{Pain assessment and analgesics}

Patients rated pain using a $10-\mathrm{cm}$ visual analogue scale (VAS) immediately after intervention and then once daily in the morning lying at rest. The analgesic policy was different in each centre, and was not influenced by the design of the study. Although the complete consumption of drugs, including analgesics, was reported for cost calculation, only analgesics in three categories are reported here: opioids, paracetamol and nonsteroidal anti-inflammatory drugs.

\section{Statistics}

The primary outcome of this study was the rate of recurrence (early plus late) of pneumothorax in the two groups. In the PD group, the expected recurrence rate was $30-50 \%$, and in the TT group 5-7\% [3]. Thus, in order to obtain a power of $\geqslant 80 \%$ with a significance level of $5 \%$ to detect a difference, $\geqslant 44$ subjects per group were required. As the majority of recurrences of PSP occur in the first year, the authors chose a mean follow-up of $\geqslant 18$ months, with the patient being clinically reviewed. Thereafter, follow-up was obtained by calling the outpatient physician and the patient if necessary.

Data are expressed as mean \pm SD. Characteristics were compared using the unpaired two-tailed t-test and Chi-squared or Mann-Whitney test for nonparametric data. p-Values of $<0.05$ were considered as significant. Analysis of variance was used to compare repeated measurements of pain by VAS.

\section{Results}

\section{Patients, hospital stay and total costs}

One-hundred and eight patients with PSP took part in the study: 20 from Montana, Switzerland; 26 from Marseille, France; 19 from Nijmegen, The Netherlands; 12 from Basel, Switzerland; five from Yvoir, Belguim; nine from Turnhout, Belguim; and 17 from Brescia, Italy. There were no differences between the two groups in characteristics of the patients, duration of drainage or hospital stay (table 2).

No patient was excluded because of conversion to general anaesthesia during thoracoscopy. The immediate success rate was significantly different between the two therapeutic approaches: before leaving the hospital 10 out of $47(21 \%)$ PD patients required a secondary talcage after prolonged drainage ( $>7$ days), whereas only one out of $61(2 \%, \mathrm{p}<0.01)$ TT patient required surgery as a supplementary procedure after $>7$ days of unsuccessful chest tube drainage.

Total costs were based on the tariffs at Conception Hospital, Marseille, France, and calculated taking into account all costs generated in 20 patients randomly selected in each group. The costs of four out of $20 \mathrm{PD}$ patients who proceeded to talcage were

Table 2. - Patient characteristics

\begin{tabular}{lcc}
\hline & $\begin{array}{c}\text { Thoracoscopic } \\
\text { talcage }\end{array}$ & $\begin{array}{c}\text { Pleural } \\
\text { drainage }\end{array}$ \\
\hline Subjects $n$ & 61 & 47 \\
Age yrs & $28 \pm 8(16-49)$ & $27 \pm 7(18-43)$ \\
Male \% & 70 & 68 \\
Smokers \% & 72 & 55 \\
Recurrent PSP \% & 77 & 64 \\
Hospital stay & $8 \pm 3.6$ & $7.4 \pm 3.9$ \\
$\quad$ duration days & $5.4 \pm 3.8$ & $5.3 \pm 3.3$ \\
$\quad \begin{array}{l}\text { duinage } \\
\text { duration days }\end{array}$ & & \\
\hline
\end{tabular}

Data are presented as mean \pm SD unless otherwise stated. PSP: primary spontaneous pneumothorax. 
Table 3. - Costs $^{\#}$ of hospitalisation and total costs ${ }^{\#}$ per patient for thoracoscopic talcage and pleural drainage

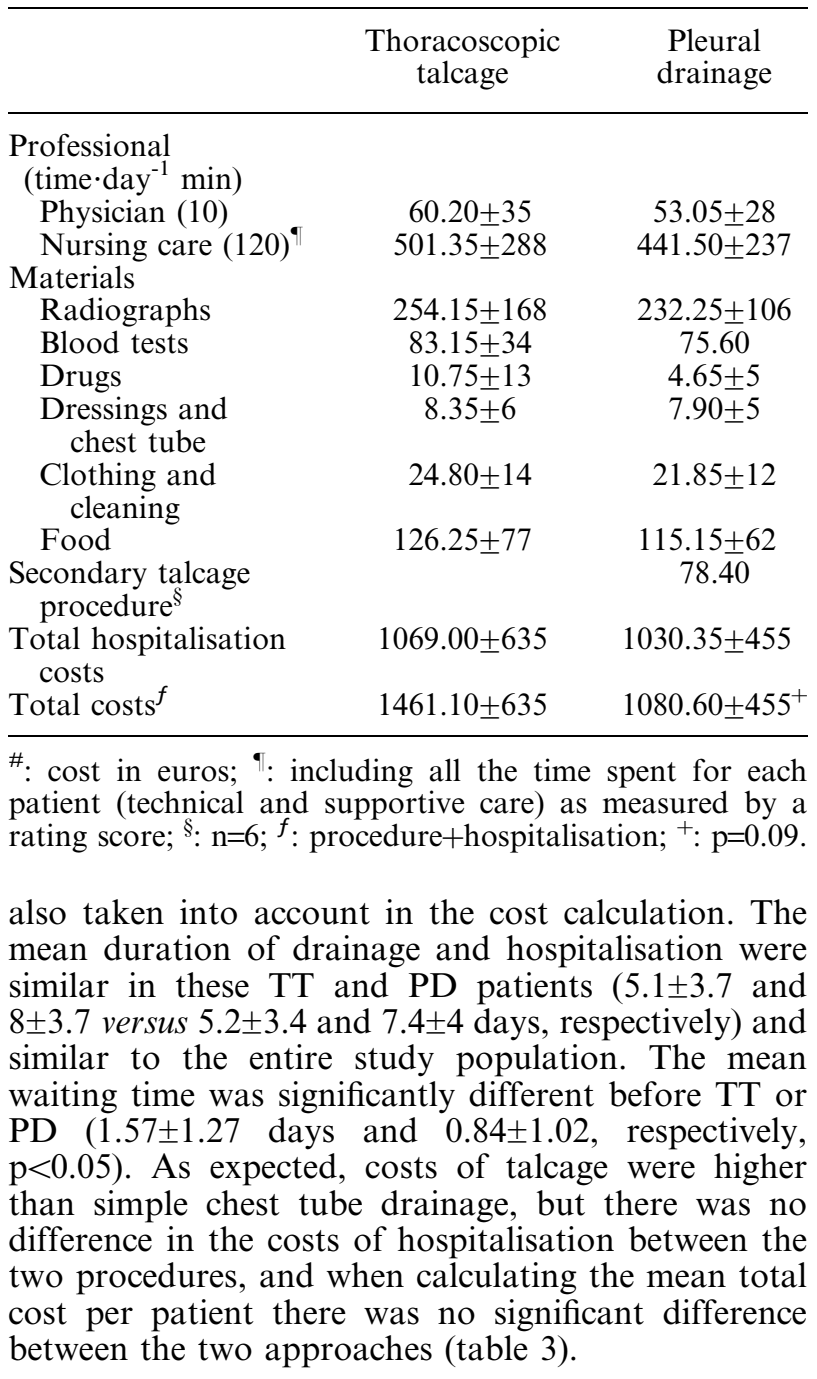

Complications, side-effects, pain control and analgesic regimen and working ability

No complications or side-effects were recorded in any patient at any time, apart from pain measured by VAS and low-grade fever in 12 patients after talc pleurodesis for 1 or 2 days. All patients received analgesic treatment, but surprisingly, four out of seven centres did not routinely use opioids even after

Table 4.-Analgesic use after thoracoscopic talcage or pleural drainage

\begin{tabular}{lcc}
\hline & $\begin{array}{c}\text { Thoracoscopic } \\
\text { talcage }\end{array}$ & $\begin{array}{c}\text { Pleural } \\
\text { drainage }\end{array}$ \\
\hline $\begin{array}{l}\text { Subjects n } \\
\text { Opioids (\%) }\end{array}$ & 61 & 47 \\
$\begin{array}{l}\text { Paracetamol, } \\
\text { propacetamol (\%) }\end{array}$ & $48(79)$ & $25(52)$ \\
NSAID (\%) & $37(60)$ & $22(47)$ \\
\end{tabular}

Data are presented as $\mathrm{n}(\%)$ unless otherwise stated. NSAID: nonsteroidal anti-inflammatory drugs.
TT. There was no significant difference in the type of analgesics between the two groups, although more TT patients received opioids than PD patients (table 4). Pain score was slightly, but significantly higher in TT patients during the first 3 days (fig. 1a). However, pain control policy was not the same in the different participating hospitals. In the three centres where opioids were used systematically after talc poudrage, there was no difference in pain score at any time between these 24 TT patients and the 14 PD patients (fig. 1b). Moreover, when comparing the 48 TT patients
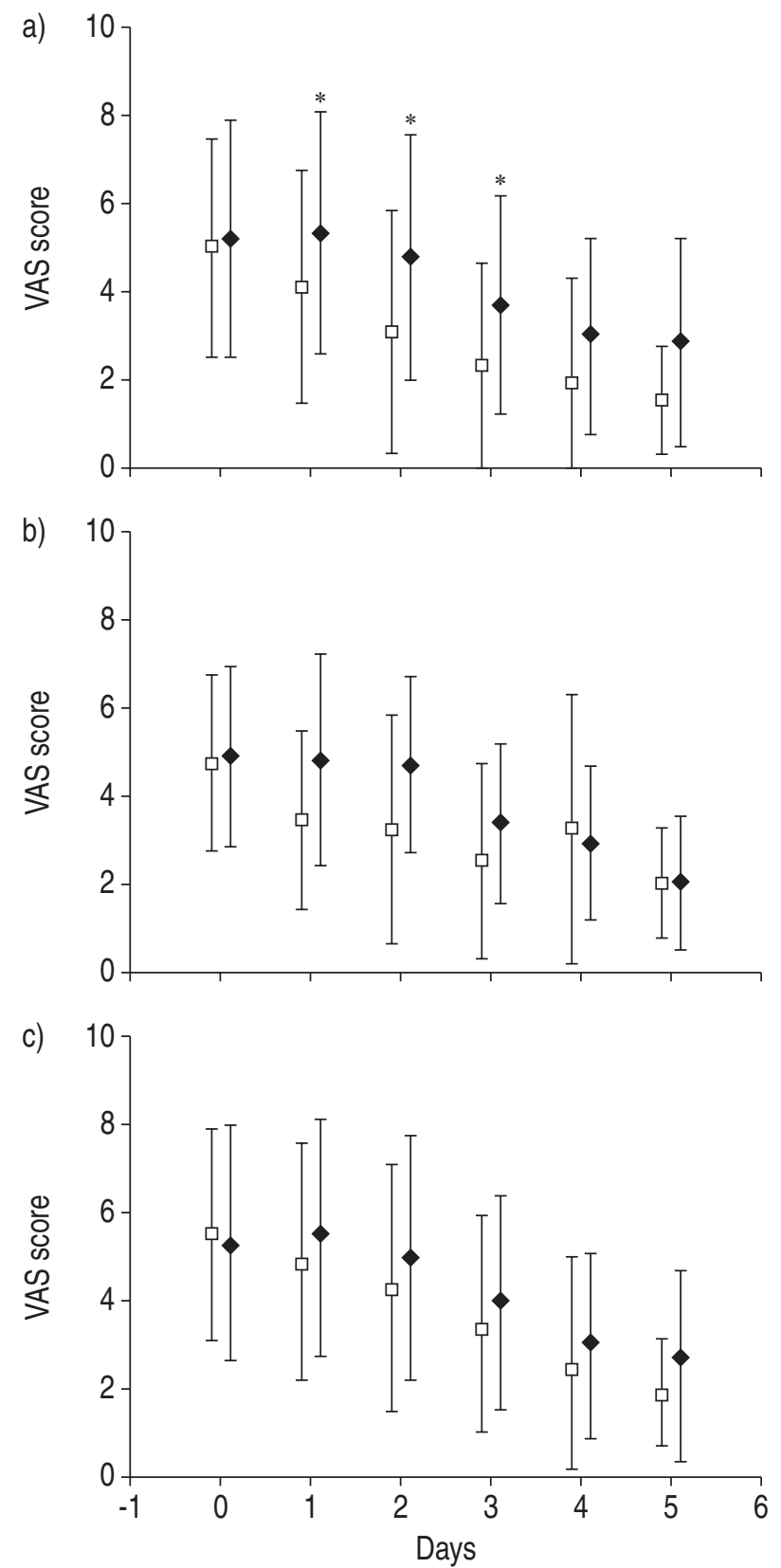

Fig. 1.-Visual analogue scale (VAS) pain score after thoracoscopic talcage (TT, $\bullet$ ) and pleural drainage (PD, $\square$ ) in a) all patients (TT $n=67$ and PD $n=47$ ), b) in patients in centres which systematically used opioids after TT (TT $n=24$ and PD $n=14)$, and c) in TT and PD patients systemically receiving opioids (TT $n=48$ and PD $\mathrm{n}=25) .{ }^{*}: \mathrm{p}<0.05$. 


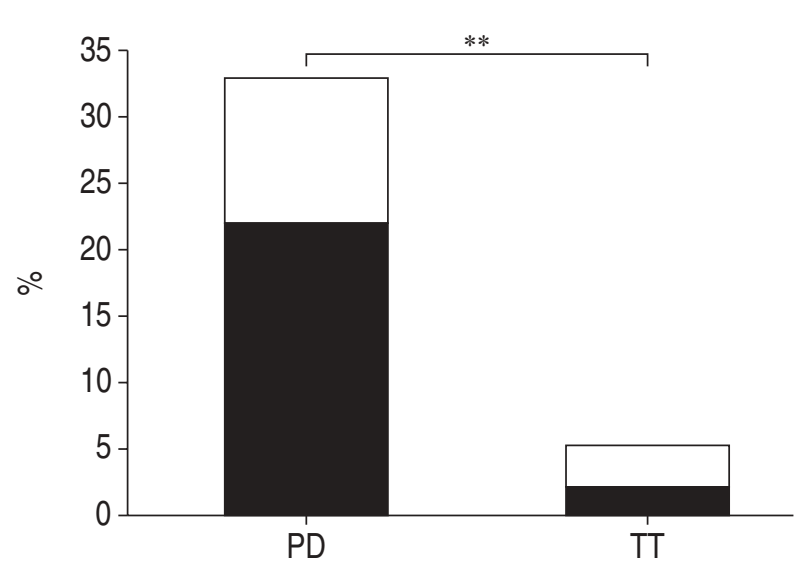

Fig. 2.-Immediate ( $\square$ ) and long-term ( $\square$ ) recurrence rates of pneumothorax after pleural drainage (PD) or thoracoscopic talcage (TT). **: $\mathrm{p}<0.01$.

and the 25 PD patients who systematically received opioids, there was again no difference in pain score at any time (fig. 1c).

One month after leaving the hospital, there was no difference between TT and PD patients in residual pain or full working ability: 20 out of $58(34 \%)$ versus 10 out of $47(21 \%, p=0.5)$ and 36 out of $61(59 \%)$ versus 26 out of $39(67 \%, \mathrm{p}=0.6)$, respectively.

\section{Long-term follow-up and recurrence rate}

Mean follow-up was 60.5 \pm 34.3 (29-79) months and $54.0 \pm 33.2$ (28-74) months, respectively in TT and PD groups. The total recurrence rate, i.e. immediate and long-term recurrence rate, was substantially higher in PD patients (16 out of $47,34 \%$ ) than in TT patients three out of $59(5 \%, \mathrm{p}<0.01$, fig. 2). Unfortunately, two cases in the TT group were lost at follow-up.

\section{Discussion}

The choice of treatment of patients with spontaneous pneumothorax depends on the patient's presentation with a first time or recurrent pneumothorax and the presence of a primary or secondary pneumothorax, i.e. a pneumothorax related to some underlying lung disease [11].

In this study, looking at PSP requiring chest tube drainage, excellent overall results were obtained using simple talc pleurodesis by thoracoscopy without any resection or coagulation of blebs or bullae. As seven centres participated in the study, there were not identical numbers of patients in the two groups because the randomisation blocks were too large. The authors recognise that it would have been preferable to have smaller blocks with better central monitoring of the distribution between the two groups, especially as some centres included few patients in the study. As there was no difference in patient characteristics between the two groups, this is unlikely to affect the results. Moreover, if the worst case scenario is taken, with even numbers in both groups (54 versus 54), seven patients from the talcage group would have been in the chest tube drainage group. If none of these seven patients had developed a recurrence, the total recurrence rate would have been 15 out of 54 in the PD group versus three out of 54 in the TT group. Such a difference in recurrence rate between TT and PD would still remain significant $(\mathrm{p}<0.01)$.

Other than pain and fever, no complications were recorded after talc pleurodesis, which is not surprising because it has been shown previously that talc pleurodesis under local anaesthesia is safe [2, 8-10], although these findings contrast with a few recent studies [14, 15]. In terms of recurrence of spontaneous pneumothorax after talc pleurodesis, the present results are comparable with other surgical [16-22] and medical $[2,3,8,23,24]$ studies, and support the hypothesis that the site of rupture of the visceral pleura might be other than bullae or blebs [25]. This suggests that a simple and efficient pleurodesis might be sufficient to control air leak in spontaneous pneumothorax. However, as previously suggested by JANSSEN et al. [9], another prospective controlled study, comparing recurrence rate of spontaneous pneumothorax after pleurodesis alone to pleurodesis and bullectomy in patients with visible lesions, is required to prove such a hypothesis. The present study confirms results of previous nonrandomised studies $[2,8,10,23,26-28]$, and shows that TT under local anaesthesia is rapid, safe, inexpensive and highly effective in preventing recurrence of spontaneous pneumothorax. It is not surprising that the costs of talc pleurodesis were very close to the costs of conservative treatment by chest tube drainage, because medical thoracoscopy is a nonsurgical technique that has been performed throughout Europe since the beginning of the 20th century [2, 29]. The procedure is routinely performed under local anaesthesia and spontaneous ventilation in a simple endoscopic suite. Boutin et al. [30] recently showed that the cost of treating pneumothorax by this technique was about one-third of that of VATS.

This study confirms the results of a recent retrospective study [11] that showed that it is more costeffective to treat PSP immediately with VATS, than to wait for recurrence in $30-50 \%$ of patients. There was no significant difference in total costs between the two approaches, and the authors recognise that they would have obtained a further reduction of $62 \%$ in the cost of treatment if they had simply used thoracoscopic talc pleurodesis. The present authors did not take the costs of rehospitalisation for late recurrence into account, which would certainly have further increased overall costs in the chest tube group, as there was only a three out of $59(5 \%)$ chance of late recurrence in the talc pleurodesis group, but a six out of $47(13 \%)$ chance in the conservative group. Due to the design of the study, these costs could not be calculated, which would have further favoured immediate talc pleurodesis under thoracoscopy. A careful study of costs was carried out for each patient, and the present authors are unaware of any other prospective study of this type. For practical reasons, 20 patients in each group were randomly selected to 
calculate the mean total cost per patient of each approach. As the rate of immediate failure of PD was the same for these 20 patients as for all the patients who benefited from PD, one may reasonably conclude that they were representative of all the patients with PD. There was immediate failure in one case out of 61 $(2 \%)$ in patients who underwent immediate TT, but due to random selection, this patient was not included in the 20 chosen for cost calculation. The mean waiting time before both interventions was short but different between the two procedures. If the patients had not been participating in the study, the waiting time could have been easily avoided, which would have decreased the length of hospital stay. The difference in cost between the two interventions, PD and TT, is explained by the necessary preliminary check-up by the anaesthetist before thoracoscopy, and the need for more material and manpower for thoracoscopy. The hospitalisation costs were similar in the two groups, as postinterventional nursing and medical care were the same. It could be argued that the cost of medical VATS was deliberately underestimated. However, the study was multicentre and the authors did not interfere with local rules for performing TT and analgesia before, during or after intervention. The only requirement was to perform the procedure under local anaesthesia and spontaneous ventilation without intubation at any time. The manpower used for thoracoscopy was not the same in the participating centres; some hospitals used no anaesthesiology staff. However, for the calculation of mean cost of thoracoscopy, the maximum manpower used was considered, i.e. two anaesthetists. No significant differences in working ability and residual pain 1 month after leaving the hospital were found between patients treated by PD or talc poudrage, confirming that thoracoscopic pleurodesis with small amount of talc does not lead to any permanent clinical disablement.

Pain has been reported after TT in isolated cases [23], but this recent study did not report the analgesic regimen used. Therefore, differences in pain felt by patients after talc pleurodesis or PD were assessed in this study. The analgesic policy of participating hospitals was not influenced. The analgesic regimen for each patient was recorded, although not reported, and showed that pain was significantly greater after TT in centres that did not use any opioids, whereas no difference in pain score at any time was found between the two groups when patients systematically received opioids (fig. 1). The present authors believe that the results presented here are true because daily VAS assessment of pain was carried out under standardised conditions [31]. However, it remains surprising that not all the involved centres systematically used opioids during and after talcage, as there were no serious sideeffects related to their use. These results suggest underuse of analgesics, especially opioids in this situation. Pulmonologists performing thoracoscopy should learn better use of more efficient therapeutic tools from anaesthetists [32], such as patient-controlled analgesia. This method has been extremely important in changing the minds of physicians and nursing staff with respect to individual pain management [33].
In conclusion, this multicentre prospective study shows that simple thoracoscopic talcage under local anaesthesia is a safe, cost-effective treatment for patients with primary spontaneous pneumothorax requiring at least chest tube drainage, with less morbidity provided there is efficient control of pain by opioids. In view of these results, patients should be informed about the recurrence rates of different treatment strategies and given the choice between chest tube drainage and immediate talcage.

Acknowledgements. The authors would like to thank the Lancardis Foundation for financial support and G-J. van der Wilt and J-M. Gaspoz for their support in performing the economic analysis.

The ESMEVAT (European Study on Medical Video-Assisted Thoracoscopy) team: study director, C. Boutin (Service de Pneumologie, Hôpital de la Conception, Marseille, France); J.G. Frey, S. Grandin, J.M. Tschopp (Centre Valaisan de Pneumologie, Montana, Switzerland); Ph. Astoul, V. Bonneau, S. Germain (Service de Pneumologie, Hôpital de la Conception, Marseille, France); J.P. Janssen, R Termeer, W. Van den Berg, F. Visser (Afdeling Longziekten, Canisius Wilhelmina Ziekenhuis, Nijmegen, The Netherlands); C.T. Bolliger, A.P. Perruchoud, C. Wyser (Abteilung für Pneumologie, Universitätskantonsspital, Basel, Switzerland); L. Delaunois (Service de Pneumologie, Cliniques Universitaires UCL de Mont-Godinne, Yvoir, Belgium), P. Driesen (St Elisabeth ZH, Turnhout, Belgium); G.P. Marchetti, G.F. Tassi (Divisione di Pneumologia, Spedali Civili, Brescia, Italy).

\section{References}

1. Melton LJ III, Hepper NG, Offord KP. Incidence of spontaneous pneumothorax in Olmsted County, Minnesota: 1950 to 1974. Am Rev Respir Dis 1979; 120: 1379-1382.

2. Boutin C, Viallat JR, Aelony Y. Practical Thoracoscopy. Berlin, Springer Verlag, 1991.

3. Van de Brekel JA, Vincent A, Duurkens M, Roland GJ, Vanderschueren RA. Results of thoracoscopy and pleurodesis with talc poudrage and thoracotomy. Chest 1993; 103: 345-347.

4. Bresticker MA, Oba J, LoCicero J, Greene R. Optimal pleurodesis: a comparison study. Ann Thorac Surg 1993; 55: 364-367.

5. Waller DA, Yoruk Y, Morritt GN, et al. Videothoracoscopy in the treatment of spontaneous pneumothorax: an initial experience. Ann $R$ Coll Surg Engl: 1993: 237-240.

6. Suter M, Berner M, Vandoni R, Cuttat JF. Traitement par thoracoscopie du pneumothorax récidivant. Helv Chir Acta 1994; 60: 465-470.

7. Hausmann M, Keller R. Thorakoskopische Pleurodese beim Spontanpneumothorax. Schw Med Wschr 1994; 124: 97-104.

8. El Khawand Ch, Marchandise FX, Mayne A, et al. Pneumothorax spontané. Résultats du talcage pleural sous thoracoscopie. Rev Mal Resp 1995; 12: 275-281.

9. Janssen JP, Schramel FMNH, Sutedja TG, Cuesta MA, 
Oosterhuis WP, Ostmus PE. Videothoracoscopic appearance of first and recurrent pneumothorax. Chest 1995; 108: $330-334$

10. Tschopp JM, Brutsche M, Frey JG. Treatment of complicated spontaneous pneumothorax by simple talc pleurodesis under thoracoscopy and local anaesthesia. Thorax 1997; 52: 329-332.

11. Schramel FMNH, Sutedja TG, Braber JCE, et al. Cost-effectiveness of video-assisted thoracoscopic surgery versus conservative treatment for first time or recurrent spontaneous pneumothorax. Eur Respir $J$ 1996; 9: 1821-1825.

12. Miller AC, Harvey JE, on behalf of Standards of Care Committee BTS. Guidelines for the management of spontaneous pneumothorax. BMJ 1993; 307: 114-116.

13. Zuili-Taieb C. Pneumothorax spontané. Etude comparative coût/efficacité entre le drainage simple et le talcage par thoracoscopie. Université de la Méditerranée. Faculté de Médecine de Marseille. Thèse. 1998.

14. Rehse DH, Aye RW, Florence MG. Respiratory failure following talc pleurodesis. Am J Surg 1999; 177: 437-440.

15. Milanez JR, Werebe EC, Vargas FS, Biscegli Jatene F, Light RW. Respiratory failure due to insufflated talc. Lancet 1997; 349: 251-252.

16. Yim AP, Liu HP. Video assisted thoracoscopic management of primary spontaneous pneumothorax. Surg Laparosc Endosc 1997; 7: 236-240.

17. Waller DA, Forty J, Morritt GN. Video-assisted thoracoscopic surgery versus thoracotomy for spontaneous pneumothorax. Ann Thorac Surg 1994; 58: 372-376.

18. Liu HP, Chang CH, Lin PJ, Hsieh MJ. Thoracoscopic loop ligation of parenchymal blebs and bullae. J Thorac Cardiovasc Surg 1997; 113: 50-54.

19. Freixinet J, Canalis E, Rivas JJ, Rodriguez-de-Castro F, Gimferrer JM, Sanchez-Lloret J. Surgical treatment of primary spontaneous pneumothorax with videoassisted thoracic surgery. Eur Respir J 1997; 10: 409411.

20. Kim KH, Kim HK, Jan JY, Kin JT, Won YS, Choi SS. Transaxillary minithoracotomy versus video assisted thoracic surgery for spontaneous pneumothorax. Ann Thorax Surg 1996; 61: 1510-1512.

21. Ishida T, Kohdono S, Fukuyama Y, et al. Videoassisted thoracoscopic surgery of bullous and bleb disorders of the lung using endoscopic stapling device. Surg Laparosc Endosc 1995; 5: 349-353.

22. Simansky DA, Yellin A. Pleural abrasion via axillary thoracotomy in the era of video-assisted thoracic surgery. Thorax 1994; 49: 922-923.

23. Noppen M, Meysman M, d'Haese J, et al. Comparison of video-assisted thoracoscopic talcage for recurrent primary versus persistent secondary spontaneous pneumothorax. Eur Respir J 1997; 10: 412-416.

24. Lange P, Mortensen J, Groth S. Lung function 22-35 years after treatment of idiopathic spontaneous pneumothorax with talc poudrage or simple drainage. Thorax 1988; 43: 559-561.

25. Schramel FMNH. Current aspects of spontaneous pneumothorax. Eur Respir J 1997; 10: 1372-1379.

26. Keller R. Thorakoskopische pleurodese beim persistierenden und rezidivierenden Pneumothorax. Zentralbl Chir 1992; 117: 267-269.

27. Viskum K, Lange P. Mortensen J: Long-term sequelae after talc pleurodesis for spontaneous pneumothorax. Pneumologie 1989; 43: 105-106.

28. Milanez JRC, Vargas FS, Filomeno LTB, Fernandez A, Jatene A, Light RW. Intrapleural talc for the prevention of recurrent pneumothorax. Chest 1994; 106: $1162-1165$.

29. Loddenkemper R, Boutin C. Thoracoscopy: present diagnostic and therapeutic indications. Eur Respir $J$ 1993; 6: 1544-1555.

30. Boutin C, Germain S. Management of spontaneous pneumothorax. Thorax 1997; 52: 836.

31. Dexter F, Chestnut DH. Analysis of statistical tests to compare visual analog scale measurements among groups. Anesthesiology 1995; 82: 896-902.

32. Gabrielczyk MR. Implementing PCA - the importance of information and control. Anaesthesia 1998; 53: 1028-1037.

33. Lehmann KA. Patient-controlled analgesia: an efficient therapeutic tool in the postoperative setting. Eur Surg Res 1999; 31: 112-121. 